\title{
A Chickenpox Pneumothorax: A Case Report of Pneumothorax Secondary to VZV Infection
}

\author{
Fuad Khalil Al-Ani', Jaseem Sirajudeen', Parampil T. Shibu Kandalam², Aminah Al Aani' \\ ${ }^{1}$ Department of General Internal Medicine, Hamad General Hospital, Doha, Qatar \\ ${ }^{2}$ Department of Medical Education, Hamad Medical Corporation, Doha, Qatar \\ Email: drjaseemsirag@gmail.com
}

How to cite this paper: Al-Ani, F.K., Sirajudeen, J., Kandalam, P.T.S. and Al Aani, A. (2019) A Chickenpox Pneumothorax: A Case Report of Pneumothorax Secondary to VZV Infection. Open Journal of Internal Medicine, 9, 78-82.

https://doi.org/10.4236/ojim.2019.93011

Received: July 4, 2019

Accepted: September 2, 2019

Published: September 5, 2019

Copyright (c) 2019 by author(s) and Scientific Research Publishing Inc. This work is licensed under the Creative Commons Attribution International License (CC BY 4.0).

http://creativecommons.org/licenses/by/4.0/

\begin{abstract}
Varicella (chickenpox) is a generalized, self-limiting viral infection that is caused by varicella zoster virus (VZV). Chickenpox commonly infects children from $2-8$ years without severe outcomes, but is particularly severe when affecting adults.

\section{Keywords}

Chickenpox, Secondary Pneumothorax, VZV Infection, VZ Pneumonia, Primary Spontaneous Pneumothorax
\end{abstract}

\section{Introduction}

Pneumonia is the main complication of adulthood varicella infection, with possible respiratory failure as a result. Pneumothorax is a rare complication in adult patients following infection with varicella pneumonia. The development of pneumothorax secondary to VZV pneumonia has been attributed to the rupture of sub-pleural necrotic nodules or the rupture of preexisting blebs due to inflammation caused by pneumonia. However, spontaneous pneumothorax in varicella has very rarely been reported.

\section{Case Report}

A 24-year-old male (Table 1), previously well, presented with sudden onset right sided pleuritic chest pain and difficulty in breathing 5 days after developing fever and rashes all over the body.

Five days prior to his admission, he developed fever, malaise and a generalized macular skin rash. The rash progressed rapidly to vesicles and pustules with crust formation. There was a positive history of exposure to two sick contacts: a 
Table 1. Sociodemographic characterisitcs of the patient.

\begin{tabular}{cc}
\hline Sociodemographic/Clinical Characteristics & Patient Characteristics \\
\hline Age & 24 \\
Gender & Male \\
Ethnicity & Indian \\
Occupation & Construction worker \\
Smoking Status & Lifelong non-smoker \\
\hline
\end{tabular}

colleague with chicken pox who was actively sick, and another who had recovered. There was no history of trauma, and no previous history of pneumothorax or obstructive pulmonary disease. The patient was a lifelong nonsmoker. Upon arrival the patient was febrile with a temp of $38.2^{\circ} \mathrm{C}, \mathrm{SpO}_{2} 100 \%$ on room air. His blood pressure was $121 / 82$, he had a pulse rate of 68 and a respiratory rate of 24 per minute. Physical examination revealed a diffuse vesiculopustular skin rash with crusts. Further examination of the chest revealed diminished breath sounds over the right upper lung field. The remainder of the systemic examination was unremarkable. Blood cell count, blood coagulation, renal and hepatic functions were all within normal ranges. A chest x-ray (Figure 1(a)) revealed a small right sided pneumothorax measuring $2 \mathrm{~cm}$ at hilum. There was no evidence of concomitant pneumonia or changes suggestive of chronic obstructive pulmonary disease.

The patient was admitted to the medical short stay unit for supportive treatment. The patient received valcyclovir 1 gm q8th hourly, high flow oxygen and oral naproxen $500 \mathrm{mg}$ bid for pain relief. Throughout his hospital course, serial $\mathrm{x}$-rays did not show any worsening of the right-sided pneumothorax. A chest $\mathrm{x}$-ray (Figure $1(\mathrm{~b})$ ) on day 2 revealed a reduction in the size the pneumothorax. The patient remained stable and showed clinical improvement, he was discharged on day 3 of admission. See Table 1 for sociodemographic characteristics of the patient (Table 1).

\section{Discussion}

Pneumonia is the main serious complication of adulthood varicella and may lead to respiratory failure. Risk factors linked to the development of varicella pneumonia include cigarette smoking [1] [2] [3], pregnancy [4], immunosuppression [5], and male sex [6].

Varicella pneumonia typically develops insidiously within one to six days after the rash has appeared with symptoms of dry cough, progressive dyspnea and tachypnea.

Prompt administration of intravenous acyclovir has been associated with clinical improvement and resolution of pneumonia in selected cases [7] [8] [9].

Pneumothorax is a rare complication in adult patients following a varicella Pneumonia. A primary spontaneous pneumothorax (PSP) occurs without a 


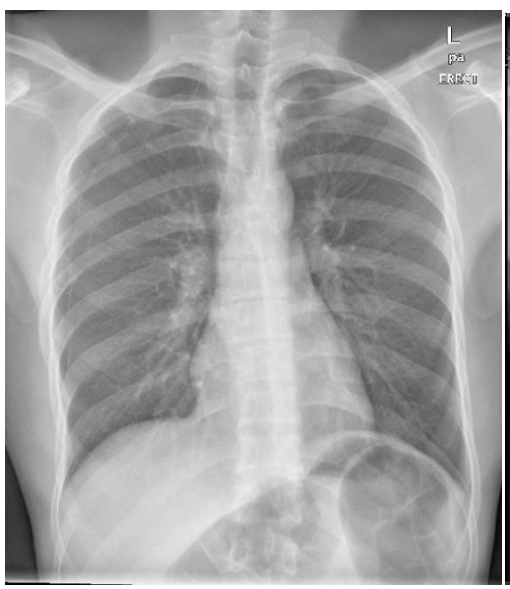

(a)

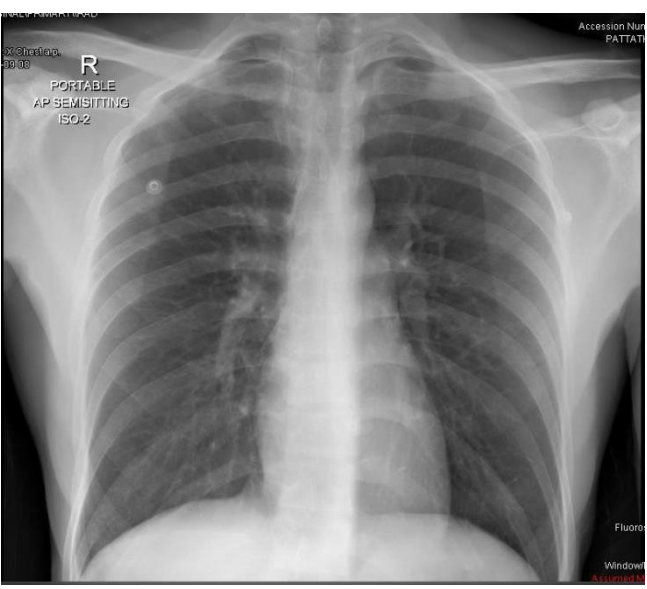

(b)

Figure 1. (a) Showing chest radiograph (PA view) upon admission revealing right-sided mild to moderate pneumothorax; (b) Showing chest radiograph (PA view) upon discharge with a reduction in size of small right-sided pneumothorax.

precipitating event in a person who does not have known lung disease. Factors that have been proposed or shown to predispose patients to primary spontaneous pneumothorax (PSP) include smoking, family history, Marfan syndrome, homocystinuria, and thoracic endometriosis [10] [11] [12] [13] [14].

On the contrary, a pneumothorax resulting as a complication of underlying lung disease is known as a secondary spontaneous pneumothorax, the most commonly associated diseases are chronic obstructive pulmonary disease, cystic fibrosis, primary or metastatic lung malignancy, and necrotizing pneumonia (e.g. bacterial or fungal pneumonia, Pneumocystis jirovecii pneumonia, and tuberculosis) [10] [15].

The development of pneumothorax secondary to VZV pneumonia has been attributed to the rupture of sub-pleural necrotic nodules or the rupture of preexisting blebs due to inflammation caused by pneumonia.

Although the exact incidence is unknown, the majority of cases with secondary pneumothorax are those accompanied with VZV pneumonia and smoking. In some cases, however, there is no examination or radiological findings to prove the presence of an underlying pneumonia [16]. In our case, we made the diagnosis of pneumothorax secondary to varicella pneumonia because it is associated with typical skin lesions of varicella, but the presence of pneumonia could not be clinically identified. As the patient was stable, a CT scan of the thorax was scheduled as outpatient; however, we sadly lost the patient to follow up as he returned to his home country. Up to our knowledge, it is extremely rare to have such complication of VZV infection without underlying pneumonia or chronic lung disease. Physicians need to be aware of this potentially fatal pulmonary event and should include it as yet another possible complication of chickenpox.

\section{Conclusion}

In patients with an active varicella infection, pneumothorax must be excluded in 
those presenting with dyspnea and chest pain, regardless of the presence or absence of pneumonia. A spontaneous pneumothorax must be immediately ruled out through a chest $\mathrm{x}$-ray. Specific precaution for a pneumothorax must be taken into consideration if a patient is a tall young man, an elderly, a smoker, or a patient with a previous history of spontaneous pneumothorax [17].

\section{Conflicts of Interest}

The authors declare no conflicts of interest regarding the publication of this paper.

\section{References}

[1] Fairley, C.K. and Miller, E. (1996) Varicella-Zoster Virus Epidemiology-A Changing Scene? The Journal of Infectious Diseases, 174, S314-S319. https://doi.org/10.1093/infdis/174.Supplement_3.S314

[2] Triebwasser, J.H., Harris, R.E., Bryant, R.E. and Rhoades, E.R. (1967) Varicella Pneumonia in Adults: Report of Seven Cases and a Review of Literature. Medicine, 46, 409-423. https://doi.org/10.1097/00005792-196709000-00003

[3] Ellis, M.E., Neal, K.R. and Webb, A.K. (1987) Is Smoking a Risk Factor for Pneumonia in Adults with Chickenpox? British Medical Journal, 294, 1002. https://doi.org/10.1136/bmj.294.6578.1002

[4] Esmonde, T.F., Herdman, G. and Anderson, G. (1989) Chickenpox Pneumonia: An Association with Pregnancy. Thorax, 44, 812-815.

[5] Fleisher, G., Henry, W., McSorley, M., et al. (1981) Life-Threatening Complications of Varicella. American Journal of Diseases of Children, 135, 896-899. https://doi.org/10.1001/archpedi.1981.02130340008004

[6] Weber, D.M. and Pellecchia, J.A. (1965) Varicella Pneumonia: Study of Prevalence in Adult Men. The Journal of the American Medical Association, 192, 572-573. https://doi.org/10.1001/jama.1965.03080190138035

[7] Schlossberg, D. and Littman, M. (1988) Varicella Pneumonia. Archives of Internal Medicine, 148, 1630-1632. https://doi.org/10.1001/archinte.1988.00380070114027

[8] Haake, D.A., Zakowski, P.C., Haake, D.L. and Bryson, Y.J. (1990) Early Treatment with Acyclovir for Varicella Pneumonia in Otherwise Healthy Adults: Retrospective Controlled Study and Review. Reviews of Infectious Diseases, 12, 788-798. https://doi.org/10.1093/clinids/12.5.788

[9] Wilkins, E.G., Leen, C.L., McKendrick, M.W. and Carrington, D. (1998) Management of Chickenpox in the Adult. A Review Prepared for the UK Advisory Group on Chickenpox on Behalf of the British Society for the Study of Infection. Journal of Infection, 36, 49-58. https://doi.org/10.1016/S0163-4453(98)80155-2

[10] Sahn, S.A. and Heffner, J.E. (2000) Spontaneous Pneumothorax. The New England Journal of Medicine, 342, 868-874. https://doi.org/10.1056/NEJM200003233421207

[11] Gobbel Jr., W.G., Rhea Jr., W.G., Nelson, I.A. and Daniel, R.A. (1963) Spontaneous Pneumothorax. The Journal of Thoracic and Cardiovascular Surgery, 46, 331.

[12] Lesur, O., Delorme, N., Fromaget, J.M., Polu, J.M. and Bernadac, P. (1990) Computed Tomography in the Etiologic Assessment of Idiopathic Spontaneous Pneumothorax. Chest, 98, 341-347. https://doi.org/10.1378/chest.98.2.341

[13] Bense, L., Lewander, R., Eklund, G., Hedenstierna, G. and Gösta Wiman, L. (1993) 


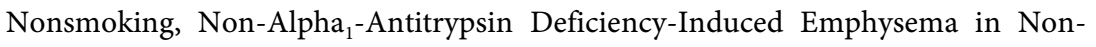
smokers with Healed Spontaneous Pneumothorax, Identified by Computed Tomography of the Lungs. Chest, 103, 433-438. https://doi.org/10.1378/chest.103.2.433

[14] Hwong, T.M., Ng, C.S., Lee, T.W., et al. (2004) Video-Assisted Thoracic Surgery for Primary Spontaneous Hemopneumothorax. European Journal of Cardio-Thoracic Surgery, 26, 893-896. https://doi.org/10.1016/j.ejcts.2004.05.014

[15] Noppen, M. and De Keukeleire, T. (2008) Pneumothorax. Respiration, 76, 121-127. https://doi.org/10.1159/000135932

[16] Park, S.W., Kang, S.H., Lee, D., Wang, H.Y. and Sung, H.S. (2003) Pneumothorax Secondary to Ipsilateral Herpes Zoster Pectoralis. Acta Dermato-Venereologica, 83, 298-299. https://doi.org/10.1080/00015550310016616

[17] Watt, A.G. (1978) Spontaneous Pneumothorax. A Review of 210 Consecutive Admissions to Royal Perth Hospital. The Medical Journal of Australia, 1, 186-188. 